
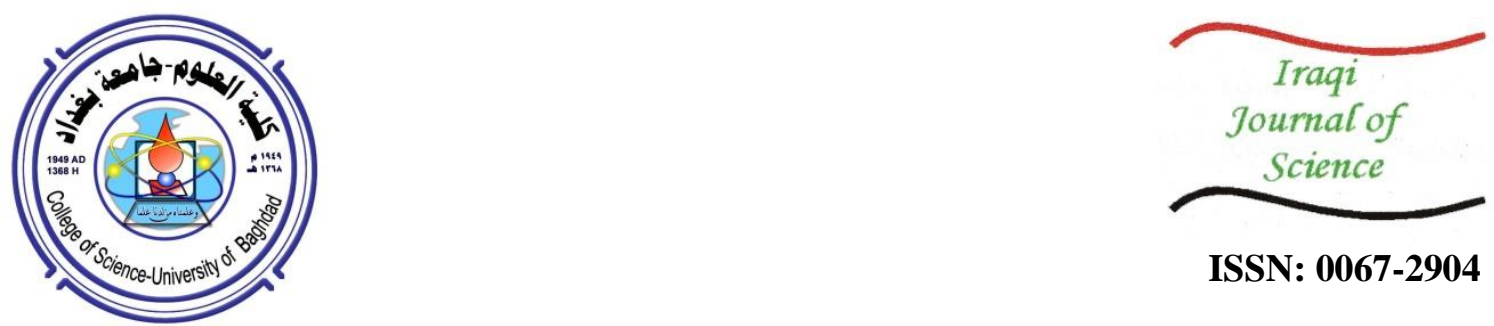

ISSN: 0067-2904

\title{
An Efficient Method for Solving Coupled Time Fractional Nonlinear Evolution Equations with Conformable Fractional Derivatives
}

\author{
Osama H. Mohammed ${ }^{1}$, Firas S. Ahmed $*^{2}$ \\ ${ }^{1}$ Department of Mathematics .and Computer Applications, college of science, Al-Nahrain University, 64055 \\ Baghdad, Iraq \\ ${ }^{2}$ Computer Unit, college of Agricultural Engineering Sciences, Baghdad University, Baghdad, Iraq
}

Received: $30 / 7 / 2020 \quad$ Accepted: $31 / 8 / 2020$

\begin{abstract}
In this article, an efficient reliable method, which is the residual power series method (RPSM), is used in order to investigate the approximate solutions of conformable time fractional nonlinear evolution equations with conformable derivatives under initial conditions. In particular, two types of equations are considered, which are time coupled diffusion-reaction equations (CD-REs) and MKdv equations coupled with conformable fractional time derivative of order $\alpha$. The attitude of RPSM and the influence of different values of $\alpha$ are shown graphically.
\end{abstract}

Keywords: Fractional differential equations (FDEs); Residual power series method (RPSM); Nonlinear evolution equations.

$$
\begin{aligned}
& \text { طريقة كفوءة لحل معادلات التطور غير الخطية الزمنية ذات الرتبة الكسرية التوافقية } \\
& \text { اسامة حميد محمد ، فراس شاكر احمد *2 }
\end{aligned}
$$

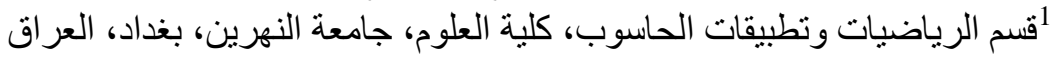

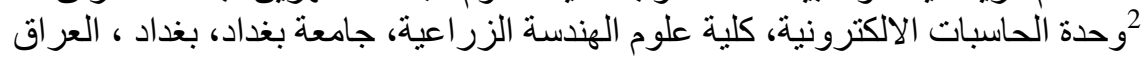

$$
\begin{aligned}
& \text { الخلاصة }
\end{aligned}
$$

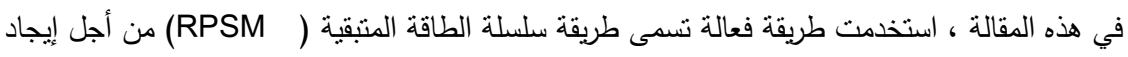

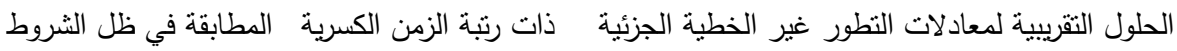

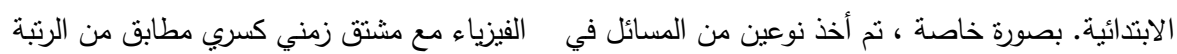

$$
\begin{aligned}
& \text { م.عرض سلوك طريقة (RPSM) وتأثيرها ولقيم } \alpha \text { مختلفة وقد تم استعراض ذلك بيانياً. }
\end{aligned}
$$

\section{Introduction}

Recently, the subject of fractional calculus has been gaining a considerable attention from various authors due to its important role in many applications. Fractional derivatives can be considered as a generalization of integer derivatives that have been widely used in characterizing the biological and physical phenomena[1-4]. There are many definitions for the fractional order derivatives, such as those reported by Riemann-Liouville, Caputo, and Grunwald-Letnikov, etc.[5- 7]. Khalil et al.[8, 9] were the first who proposed a new fractional derivative, viz. the conformable fractional derivative (CFD) to take control of the remarkable problem that had occurred in the Riemann-Liouville and Caputo fractional derivatives, which is the inheritance of the nonlocal properties from the integral. Consequently, various numerical or semi numerical methods, for example the Adomain decomposition method [10], generalized Mittag-Leffler function method and Sumudu transform method [11],

*Email: firas.shakir@ coagri.uobaghdad.edu.iq 
homotopy perturbation method [12], and variational iteration method [13], were discovered to provide the approximate solutions of FDEs. The RPSM was used successfully to produce a series of solutions for tumor models[14]. RPSM was used to investigate a numerical solution for the fractional Burger equation[15]. The exact analytical solution of the time-fractional Schrodinger equation was found in another work [16]. The main aim of this paper is to employ RPSM for two models of nonlinear FDEs of special interest physically, in terms of the convergent fractional power series. The rest of this article is arranged as follows: In section 2 some preliminaries are given. In section 3 we describe the RPSM. The models of the proposed study are described in sections 4 and 5. Numerical simulations are drawn in section 6. Finally, the conclusions are presented in section 7.

\section{Preliminaries}

Definition 2.1[8]: Given a function $y:[0, \infty) \rightarrow \mathbb{R}$, then the conformable fractional derivative of order $\alpha$ of $y$ is defined by

$$
C D_{t}^{\alpha}(y)(t)=\lim _{\varepsilon \rightarrow 0} \frac{y\left(t+\varepsilon t^{1-\alpha}\right)-y(t)}{\varepsilon}, \forall t>0, \alpha \in(0,1]
$$

And the conformable integral of order $\alpha$ is defined by

$$
C I_{t}^{\alpha}(y)(t)=\int_{\alpha}^{t} y(x) x^{\alpha-1} d x, \alpha \geq 0
$$

Theorem 2.2 [8]: Let $\alpha \in(0,1]$ and $f$, $\mathrm{g}$ be $\alpha$-differentiable at a point $\mathrm{t}>0$. then

$$
\begin{aligned}
& \text { 1. } C D_{t}^{\alpha}(a f+b g)=a\left(C D_{t}^{\alpha} f\right)+b\left(C D_{t}^{\alpha} g\right), \forall a, b \in \mathbb{R} \\
& \text { 2. } C D_{t}^{\alpha}\left(t^{p}\right)=p t^{p-\alpha}, \forall p \in \mathbb{R}, \\
& \text { 3. } C D_{t}^{\alpha}(\lambda)=0 \text {, for all constant function } f(t)=\lambda \\
& \text { 4. } C D_{t}^{\alpha}(f g)=f\left(C D_{t}^{\alpha} g\right)+g\left(C D_{t}^{\alpha} f\right) \\
& \text { 5. } C D_{t}^{\alpha}(f / g)=(g-f) / g^{2} \\
& \text { 6. If, in addition, } f \text { is differentiable, then }\left(C D_{t}^{\alpha} f\right)(t)=t^{1-\alpha} \frac{d f}{d t}(t) \text {. }
\end{aligned}
$$

\section{An Overview of CRPSM}

We consider the following fundamental concept of RPSM operator:

$$
C D^{\alpha} u(x, t)=N(u)+R(u) .
$$

Where $N(u)$ and $R(u)$ are nonlinear and linear terms, respectively, with an initial condition (IC):

$$
\mathrm{u}(x, 0)=f(x) \text {. }
$$

The RPSM suggests the solution for Eqs.(4) as a fractional power series (FPS) about the (IC) $t=0$ as:

$$
u(x, t)=\sum_{n=o}^{\infty} f_{n}(x) \frac{t^{n \alpha}}{\Gamma(n \alpha+1)}, 0<\alpha \leq 1,-\infty<x<\infty, 0 \leq t<R .
$$

Truncating the infinite series (6) after $\mathrm{k}^{\text {th }}$ terms implies:

$$
u_{k}(x, t)=\sum_{n=o}^{k} f_{n}(x) \frac{t^{n \alpha}}{\Gamma(n \alpha+1)} .
$$

For the convergence of the FBS, refer for instance to a previous work [17].

Using Equation (5), then Eq. (7) may be expressed as:

$$
u_{k}(x, t)=f(x)+\sum_{n=1}^{k} f_{n}(x) \frac{t^{n \alpha}}{\Gamma(n \alpha+1)}, k=1,2,3, \ldots
$$

The residual function ( RF ) for Eq.(4) is defined by:

Hence, the $\mathrm{k}^{\text {th }}(\mathrm{RF}) \operatorname{Res}_{u, k}$ is

$$
\operatorname{Re} s_{u}(x, t)=C D_{t}^{\alpha} u(x, t)-N(u)-R(u) .
$$

$$
\operatorname{Re} s_{u, k}(x, t)=C D_{t}^{\alpha} u_{k}(x, t)-N\left(u_{k}\right)-R\left(u_{k}\right) .
$$


As in an earlier work [18], $\operatorname{Res}(x, t)=0$ and $\lim _{k \rightarrow \infty} \operatorname{Re} s_{k}(x, t)=\operatorname{Res}(\mathrm{x}, \mathrm{t})$. Therefore, $\mathrm{D}_{t}^{n \alpha} \operatorname{Res}(x, t)$ $=0$, which comes from theorem 2.2 , property 3 , and since $\mathrm{D}_{t}^{n \alpha}$ of $\mathrm{RF}$ coincides at $t=0$, for all $n=0,1, \ldots, k$, then,

$$
C \mathrm{D}_{t}^{n \alpha} \operatorname{Re} s(x, 0)=C D_{t}^{n \alpha} \operatorname{Re} s_{k}(x, 0)=0, \forall n=0,1, \ldots, \mathrm{k}
$$

However, finding $f_{1}(x), f_{2}(x), f_{3}(x), \ldots$ needs to solve the algebraic equations:

$$
C \mathrm{D}_{t}^{(k-1) \alpha} \operatorname{Re} s_{u, k}(x, 0)=0, k=1,2,3, \ldots
$$

\section{RPSM for solving CD-REs}

The performing of the RPSM for finding the solution of the CD-REs in terms of the FPS is represented in this section.

First consider that:

$$
\begin{aligned}
& C D_{t}^{\alpha} u=u(1-u-v)+u_{x x}, \\
& C D_{t}^{\alpha} v=v_{x x}-u v, \\
& u(x, 0)=\frac{e^{k x}}{\left[1+e^{0.5 k x}\right]^{2}}, \\
& \mathrm{v}(x, 0)=\frac{1}{\left[1+e^{0.5 k x}\right]} .
\end{aligned}
$$

and the exact solution when $\alpha=1$ is given by a previous work [19] as:

$$
\begin{aligned}
& u(\mathrm{z})=\frac{e^{k z}}{\left[1+e^{0.5 k z}\right]^{2}}, \\
& \mathrm{v}(\mathrm{z})=\frac{1}{\left[1+e^{0.5 k z}\right]} .
\end{aligned}
$$

where, $z=x+c t, k$ is constant, and $C D_{t}^{\alpha} u, C D_{t}^{\alpha} v$ symbolize the conformable fractional order derivative w.r.t. $\mathrm{t}$ for the functions $u$ and $v$, respectively. The solution of problems (13) - (16) in a FPS expansion about the (IC) $t=0$ is given as follows:

$$
\begin{gathered}
u(x, t)=\sum_{n=o}^{k} f_{n}(x) \frac{t^{n \alpha}}{\Gamma(n \alpha+1)}, 0<\alpha \leq 1, \\
\mathrm{v}(x, t)=\sum_{n=o}^{k} g_{n}(x) \frac{t^{n \alpha}}{\Gamma(n \alpha+1)}, 0<\alpha \leq 1 .
\end{gathered}
$$

The $\mathrm{k}^{\text {th }}$ truncated series of $u(x, t)$ and $v(x, t)$ is defined by:

$$
\begin{aligned}
& u_{k}(x, t)=\sum_{n=o}^{\infty} f_{n}(x) \frac{t^{n \alpha}}{\Gamma(n \alpha+1)}, \\
& \mathrm{v}_{k}(x, t)=\sum_{n=o}^{\infty} g_{n}(x) \frac{t^{n \alpha}}{\Gamma(n \alpha+1)} .
\end{aligned}
$$

It is obvious that $f_{0}(x)$ and $\mathrm{g}_{0}(x)$ can be obtained directly from the initial conditions given by Eqs. (15) and (16), hence:

$$
\begin{aligned}
& f_{0}(x)=\frac{e^{k x}}{\left[1+e^{0.5 k x}\right]^{2}}, \\
& \mathrm{~g}_{0}(x)=\frac{1}{\left[1+e^{0.5 k x}\right]} .
\end{aligned}
$$

Furthermore, we rewrite Eqs. (21) and (22) as : 


$$
\begin{aligned}
& u_{k}(x, t)=\frac{e^{k x}}{\left[1+e^{0.5 k x}\right]^{2}}+\sum_{n=1}^{k} f_{n}(x) \frac{t^{n \alpha}}{\Gamma(n \alpha+1)}, \\
& \mathrm{v}_{k}(x, t)=\frac{1}{\left[1+e^{0.5 k x}\right]}+\sum_{n=1}^{k} g_{n}(x) \frac{t^{n \alpha}}{\Gamma(n \alpha+1)} .
\end{aligned}
$$

Let us define the RF of Eqs. (19) and (20) as follows:

$$
\begin{aligned}
& \operatorname{Re} s_{u}(x, t)=C D_{t}^{\alpha} u-u(1-u-v)-u_{x x}, \\
& \operatorname{Re} s_{v}(x, t)=C D_{t}^{\alpha} v-v_{x x}+u v .
\end{aligned}
$$

Then the $\mathrm{k}^{\text {th }}$ residual function becomes:

$$
\begin{aligned}
& \operatorname{Re} s_{u, k}(x, t)=C D_{t}^{\alpha} u_{k}-u_{k}\left(1-u_{k}-v_{k}\right)-\left(u_{k}\right)_{x x}, \\
& \operatorname{Re} s_{v, k}(x, t)=C D_{t}^{\alpha} v_{k}-\left(v_{k}\right)_{x x}+u_{k} v_{k} .
\end{aligned}
$$

It is clear that $\operatorname{Res}(x, t)=0$ and $\lim _{k \rightarrow \infty} \operatorname{Re} s_{k}(x, t)=\operatorname{Res}(\mathrm{x}, \mathrm{t})$. Therefore $\mathrm{CD}_{t}^{n \alpha} \operatorname{Re} s_{u}(x, t)=C D_{t}^{n \alpha} \operatorname{Re} s_{v}(x, t)=0, \forall x, t$, see theorem (2.2, property 3$)$. Hence $\mathrm{CD}_{t}^{n \alpha} \operatorname{Re} s(x, 0)=C D_{t}^{n \alpha} \operatorname{Re} s_{k}(x, 0)=0, \forall k=0,1, \ldots, n$.

The coefficients of $\mathrm{f}_{n}(x)$ and $\mathrm{g}_{n}(x), \mathrm{n}=1,2, \ldots \mathrm{k}$, respectively, can be computed by solving the following system:

$$
\begin{aligned}
& \operatorname{CD}_{t}^{(k-1) \alpha} \operatorname{Re} s_{u, k}(x, 0)=0, \quad k=1,2, \ldots \\
& C D_{t}^{(k-1) \alpha} \operatorname{Re} s_{v, k}(x, 0)=0, k=1,2, \ldots
\end{aligned}
$$

By putting the obtained values of Eq. (31) in Eqs. (19) and (20), we get the desired approximate solution of (CD-REs).

The numerical behaviour of the approximate solution of $u(x, t)$ and $v(x, t)$ of problems (13) - (16), obtained by RPSM) with different values of fractional time derivative of order $\alpha$, are shown graphically in Figures- (1) - (6).

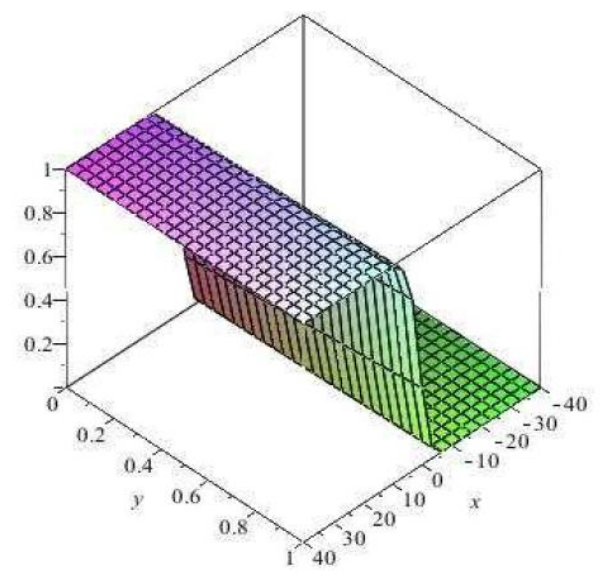

Figure 1-Result of $u$ of Eq.(13) when $\alpha=1$

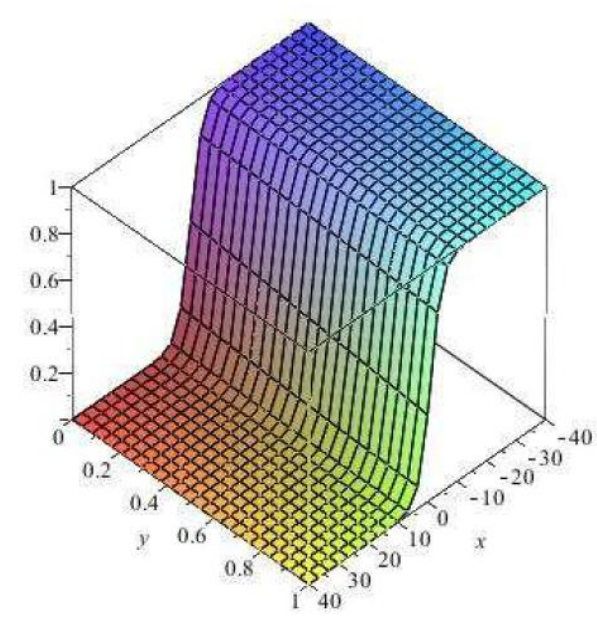

Figure 2-Result of $v$ of Eq.(14) when $\alpha=1$ 


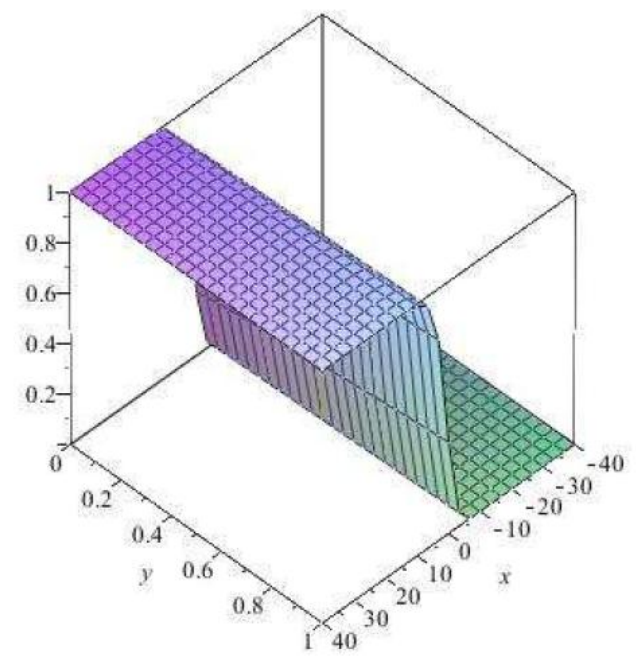

Figure 3-Closed form of $u$ of Eq.(13) when $\alpha=1$

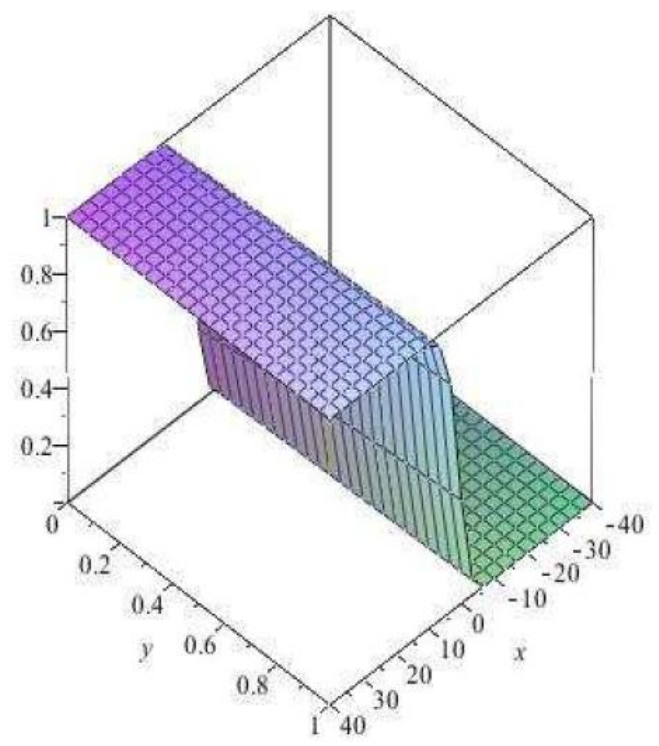

Figure - 5: Result of $u$ of Eq.(13) when $\alpha=3 / 4$

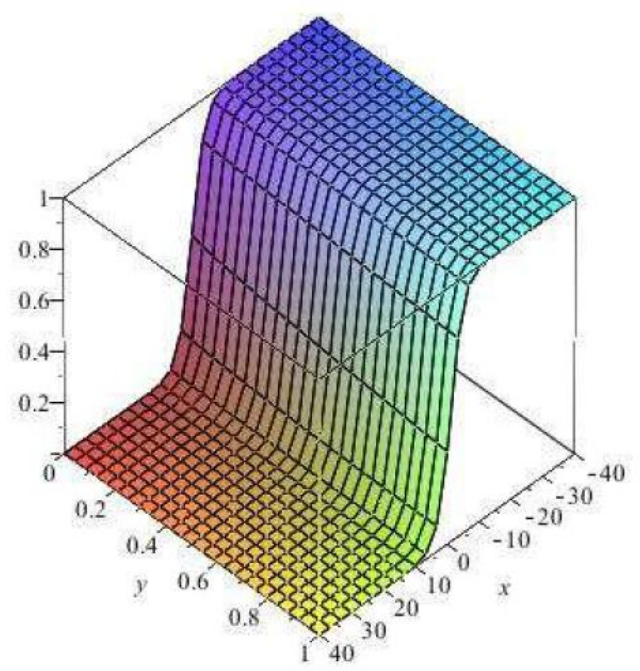

Figure 4-Closed form of $v$ of Eq.(14) when $\alpha=1$

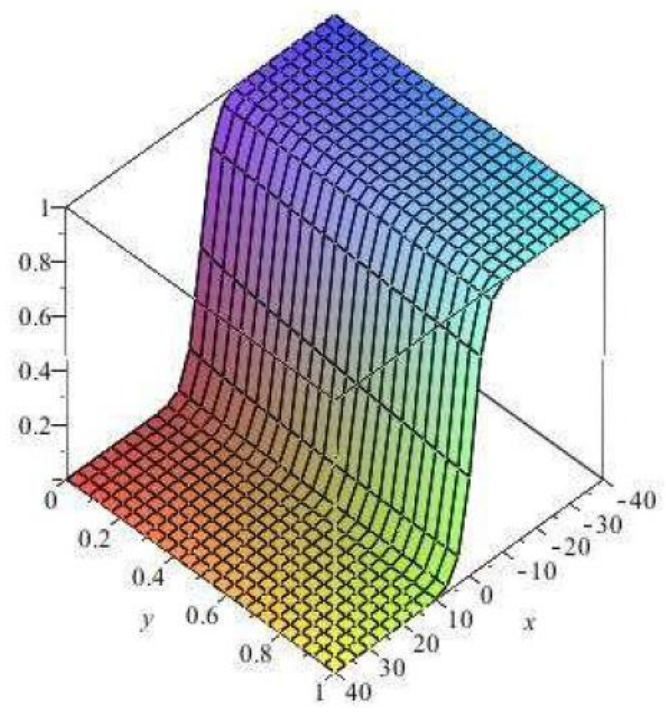

Figure - 6: Result of $v$ of Eq.(14) when $\alpha=3 / 4$

The below Figures- (7 and 8) represent the absolute error between the approximate solution and the closed form for different values of $x$ and $y=0.1$. 


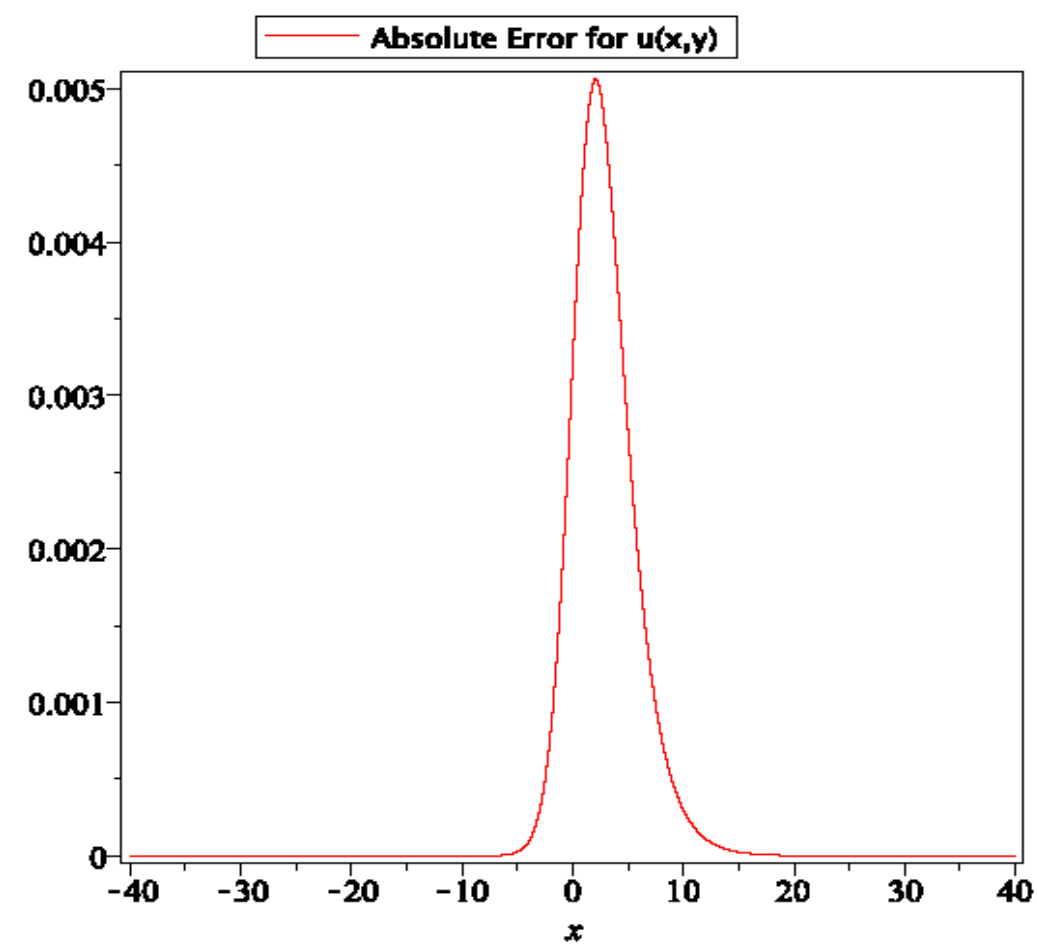

Figure 7-The absolute error between the approximate solution of $u(x, t)$ and the closed form for problems (13)-(16).

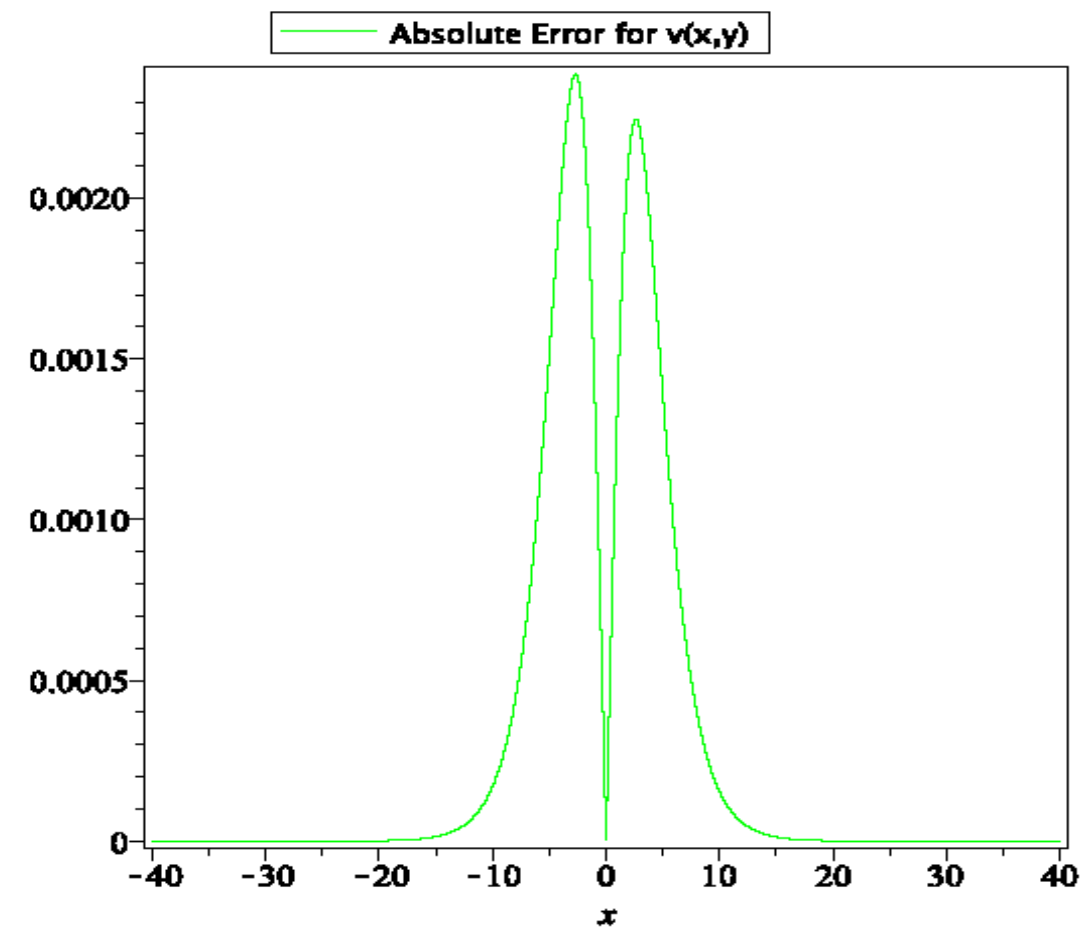

Figure 8-The absolute error between the approximate solution of $v(x, t)$ and the closed form for problems (13)-(16).

5. RPSM for solving coupled MKdv equations with a conformable fractional order derivative (CMKdv)

In this segment, the RPSM will also be considered in order to get the solution of the CD-R as FBS, as follows: 
With

$$
\begin{gathered}
C D_{t}^{\alpha} u=\frac{1}{2} u_{x x x}-3 u^{2} u_{x}+\frac{3}{2} v_{x x}+3(u v)_{x}-3 \lambda u_{x}, \\
C D_{t}^{\alpha} v=-v_{x x x}-3 v v_{x}-3 u_{x} v_{x}+3 u^{2} v_{x}+3 \lambda_{x} . \\
u(x, 0)=\frac{b_{1}}{2 k}+k \tanh [k x], \\
v(x, 0)=\frac{\lambda}{2}\left(1+\frac{b_{1}}{2}\right)+b_{1} \tanh [k x] .
\end{gathered}
$$

The exact solution when $\alpha=1$ is given by a previous work [20], as:

$$
\begin{gathered}
u(x, t)=\frac{b_{1}}{2 k}+k \tanh [k \xi], \\
v(x, t)=\frac{\lambda}{2}\left(1+\frac{b_{1}}{2}\right)+b_{1} \tanh [k \xi] .
\end{gathered}
$$

with $\xi=x+\frac{1}{4}\left[-4 k^{2}-6 \lambda+\frac{6 k \lambda}{b 1}+\frac{3 b_{1}^{2}}{k^{2}}\right] t$, where $k, b_{1} \neq 0, \lambda$ is an arbitrary constant, $C D_{t}^{\alpha} u$, $C D_{t}^{\alpha} v$ symbolize the conformable fractional order derivative w.r.t. $\mathrm{t}$ for the functions $u$ and $v$, respectively. Then the solutions of problems (32) - (35) in a fractional power series expansion about the initial point $t=0$ are given by Eqs. (19) and (20). Also $u_{k}(x, t)$ and $v_{k}(x, t)$ are defined by Eqs. (21) and (22), respectively. Clearly, for the case $n=0$, we have from Eqs. (34) and (35) that:

$$
\begin{aligned}
& f_{0}(x)=\frac{b_{1}}{2 k}+k \tanh [k x], \\
& g_{0}(x)=\frac{\lambda}{2}\left(1+\frac{b_{1}}{2}\right)+b_{1} \tanh [k x] .
\end{aligned}
$$

Now, from Eqs. (38) and (39), we have:

$$
\begin{aligned}
& u_{k}(x, t)=\frac{b_{1}}{2 k}+k \tanh [k x]+\sum_{n=1}^{k} f_{n}(x) \frac{t^{n \alpha}}{\Gamma(n \alpha+1)}, \\
& v_{k}(x, t)=\frac{\lambda}{2}\left(1+\frac{b_{1}}{2}\right)+b_{1} \tanh [k x]+\sum_{n=1}^{k} g_{n}(x) \frac{t^{n \alpha}}{\Gamma(n \alpha+1)} .
\end{aligned}
$$

We define the RF of Eqs. (32) and (33) as follows:

Then the $\mathrm{k}^{\mathrm{th}}(\mathrm{RF})$ becomes:

$$
\begin{aligned}
& \operatorname{Re} s_{u}(x, t)=C D_{t}^{\alpha} u-\frac{1}{2} u_{x x x}+3 u^{2} u_{x}-\frac{3}{2} v_{x x}-3(u v)_{x}+3 \lambda u_{x}, \\
& \operatorname{Re} s_{v}(x, t)=C D_{t}^{\alpha} v+v_{x x x}+3 v v_{x}+3 u_{x} v_{x}-3 u^{2} v_{x}-3 \lambda v_{x} .
\end{aligned}
$$

$$
\begin{gathered}
\operatorname{Re} s_{u, k}(x, t)=C D_{t}^{\alpha} u-\frac{1}{2} u_{x x x}+3 u^{2} u_{x}-\frac{3}{2} v_{x x}-3(u v)_{x}+3 \lambda u_{x}, \\
\operatorname{Re} s_{v, k}(x, t)=C D_{t}^{\alpha} v+v_{x x x}+3 v v_{x}+3 u_{x} v_{x}-3 u^{2} v_{x}-3 \lambda v_{x} .
\end{gathered}
$$

The coefficient of the approximate solutions $u$ and $v$ of problems (32)-(35), which is represented by Eqs. (21) and (22), where $\mathrm{f}_{n}(x)$ and $\mathrm{g}_{n}(x), \mathrm{n}=1,2, \ldots \mathrm{k}$, may be obtained by solving the following algebraic system:

$$
\begin{aligned}
& \operatorname{CD}_{t}^{(k-1) \alpha} \operatorname{Re} s_{u, k}(x, 0)=0, \quad k=1,2, \ldots \\
& C D_{t}^{(k-1) \alpha} \operatorname{Re} s_{v, k}(x, 0)=0, k=1,2, \ldots
\end{aligned}
$$

By putting the obtained values in Eqs. (19) and (20), we get the desired approximate solution of CMKdv. 
Figures.(9) - (14) present the dynamic and attitude of the (RPSM) solutions $u(x, t)$ and $v(x, t)$ of problem (32) - (35) under the influence of the replacing in the values of fractional order $\alpha$.

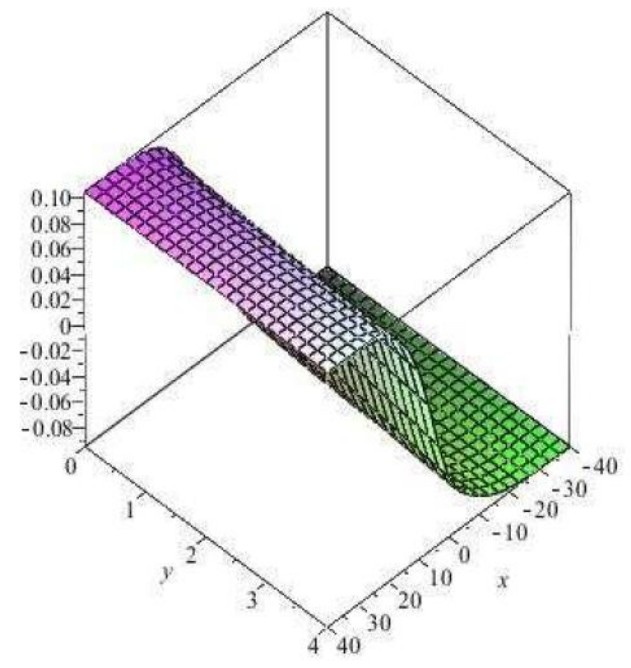

Figure - 9: Result of $u$ of Eq.(32) when $\alpha=1$

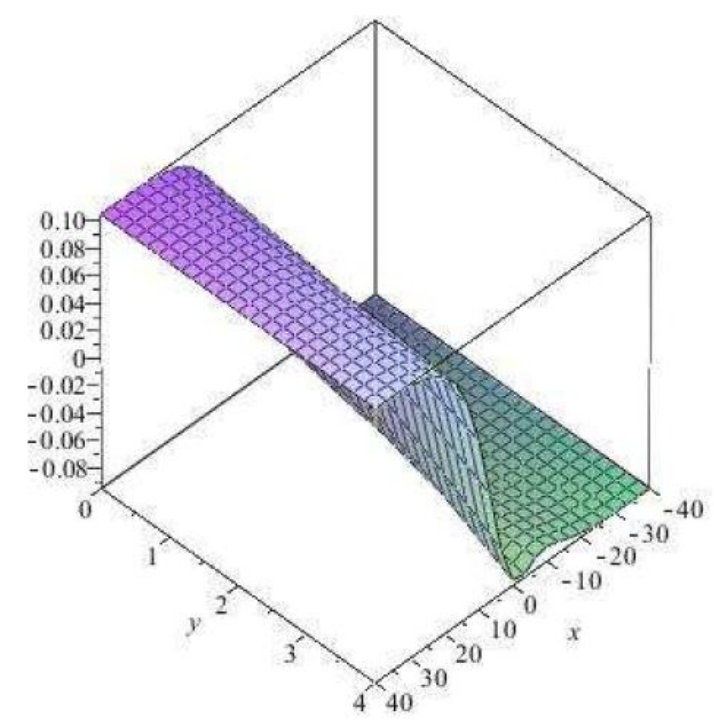

Figure 11-Closed form of $u$ of Eq.(32) when $\alpha=1$

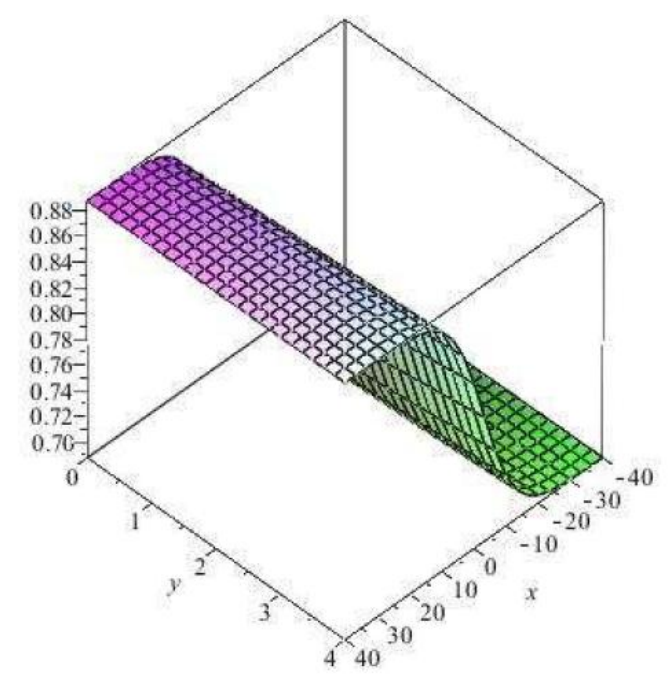

Figure - 10: Result of $v$ of Eq.(33) when $\alpha=1$

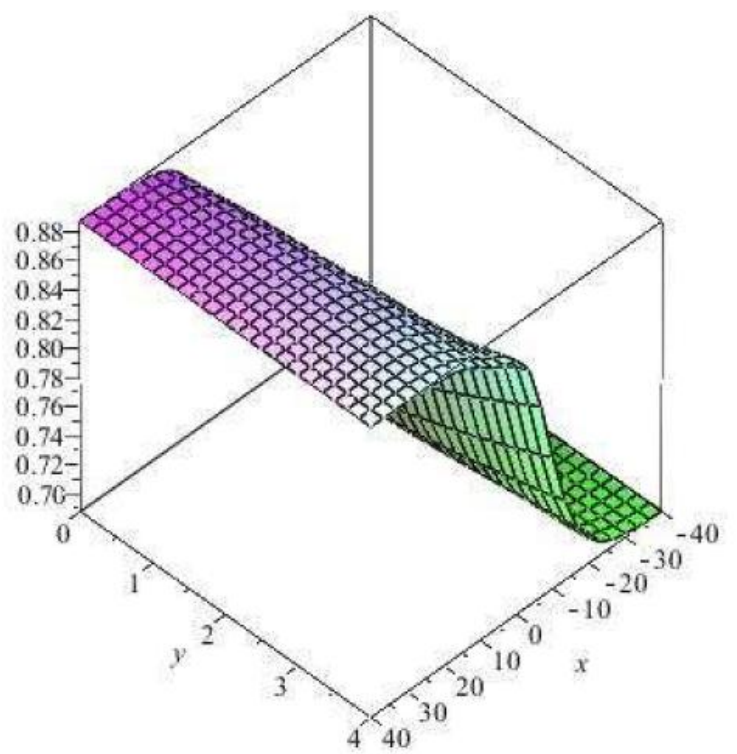

Figure 12- Closed form of $v$ of Eq.(33) when $\alpha=1$ 


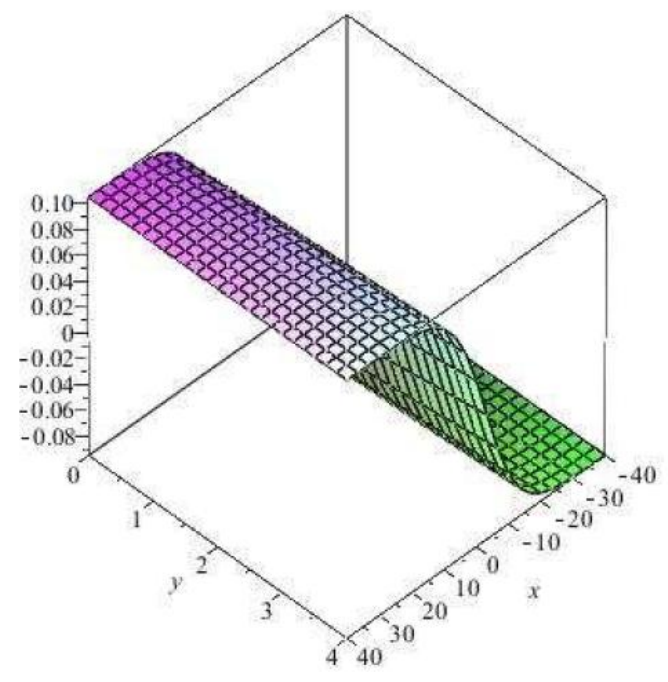

Figure 13-Result of $u$ of Eq.(32) when $\alpha=1 / 2$

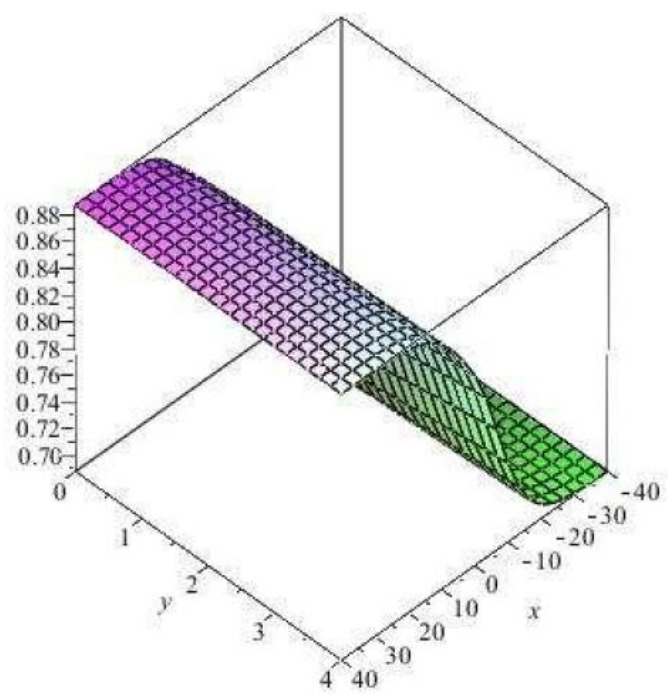

Figure 14-Result of $v$ of Eq.(33) when $\alpha=1 / 2$

Below, Figures-(15-16) represent the absolute error between the approximate solution and the closed form for different values of $x$ and $y=0.1$.

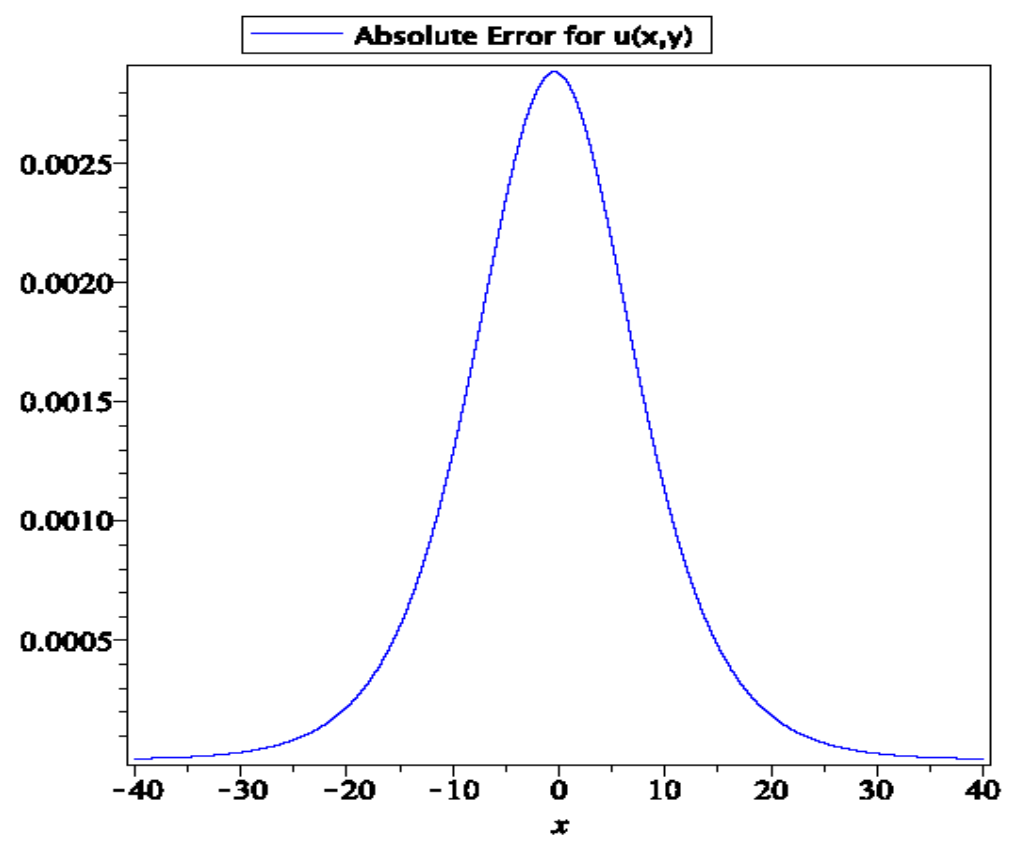

Figure 15-The absolute error between the approximate solution of $u(x, t)$ and the closed form for problems (32)-(35). 


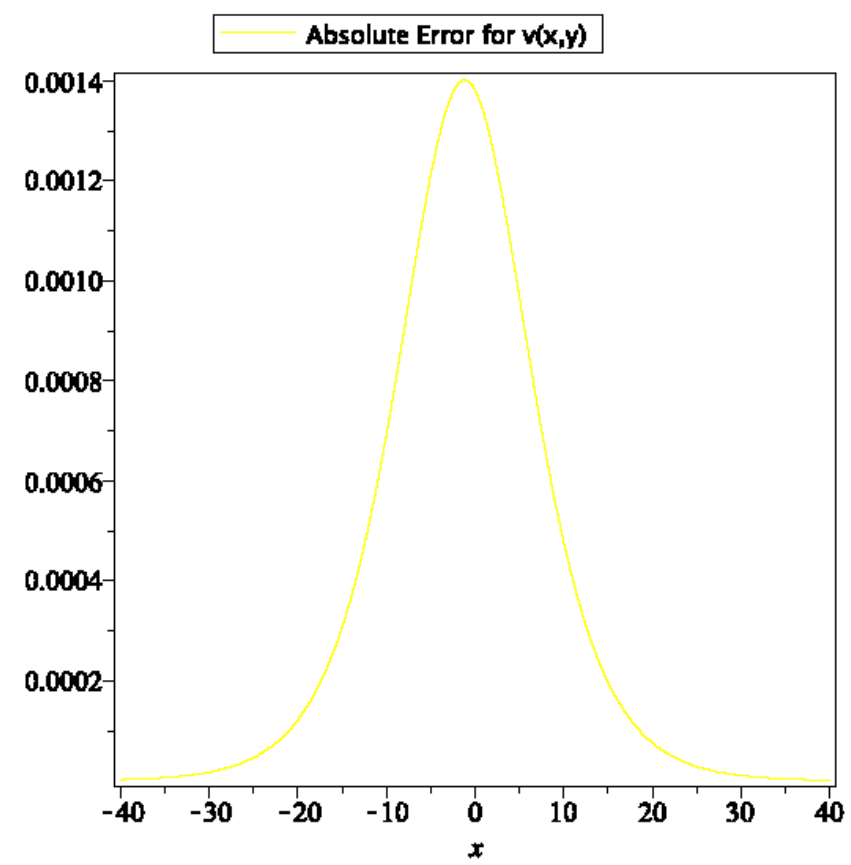

Figure 16-The absolute error between the approximate solution of $v(x, t)$ and the closed form for problems (32)-(35)

\section{Numerical Simulation}

In the previous sections the accuracy and efficiency of the proposed method were verified. The actions of the approximate solution $u(x, y)$ and $v(x, y)$ for problems (13)-(16) and (32)-(35) for different values of $\alpha$ and $x$ at $t=0.2$ are given in Figures (17)-(20).

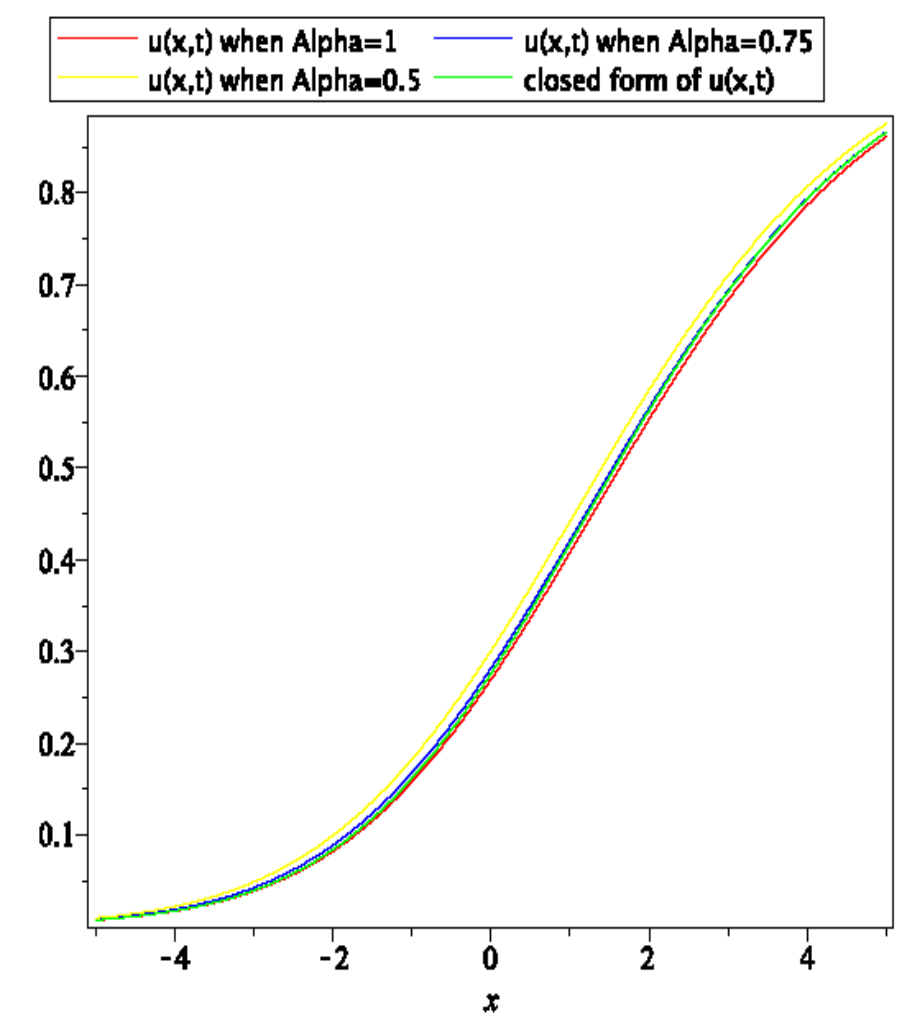

Figure 17-The action of $u(x, t)$ of problems (13)-(16). 


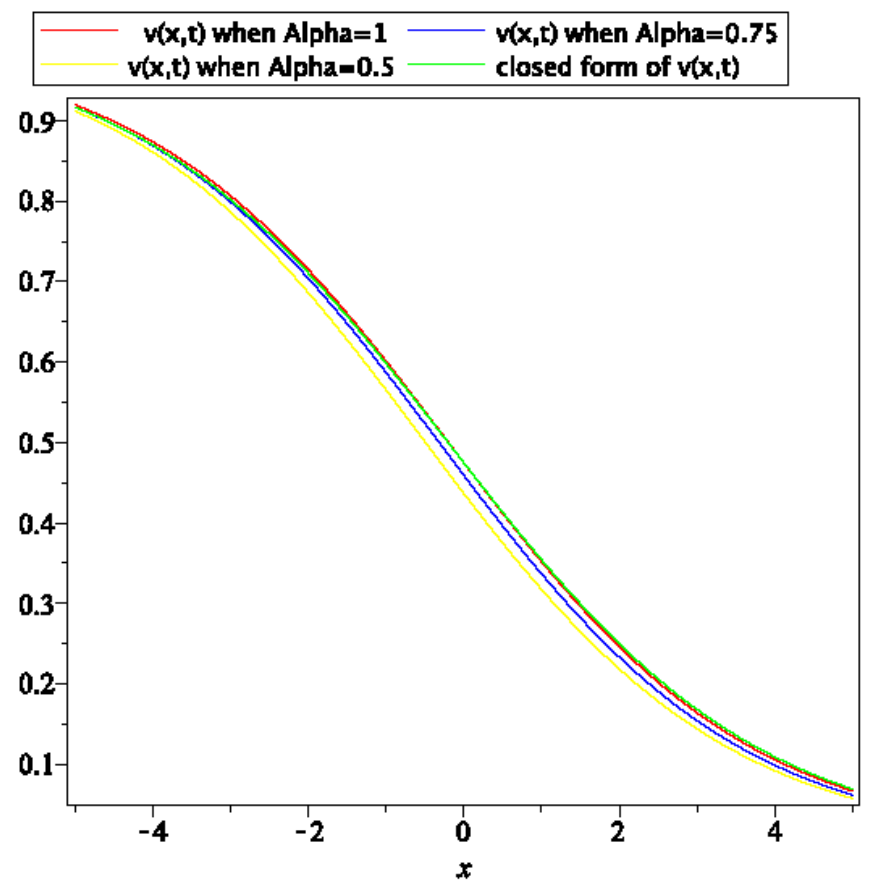

Figure 18-The action of $v(x, t)$ of problems (13)-(16).

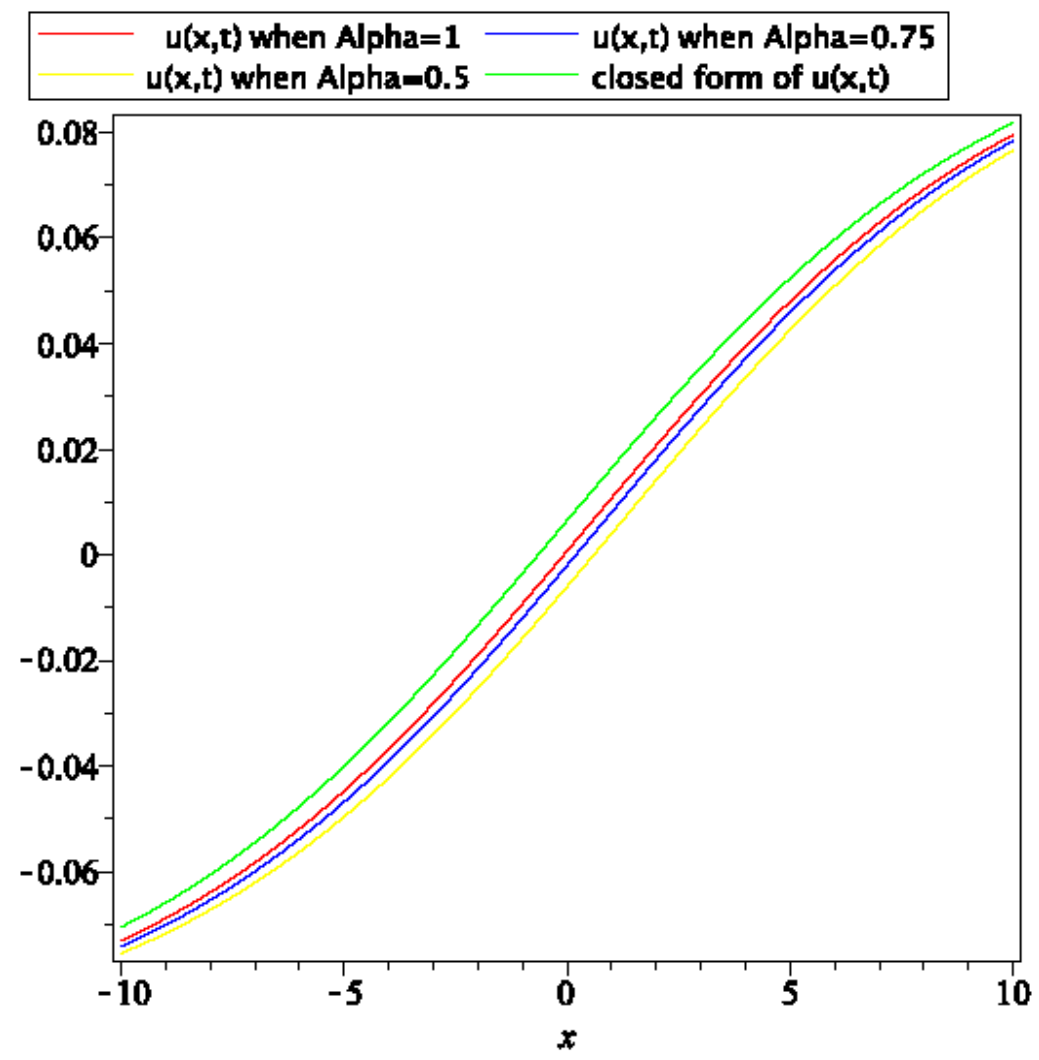

Figure 19- The action of $u(x, t)$ of problems (32)-(35). 


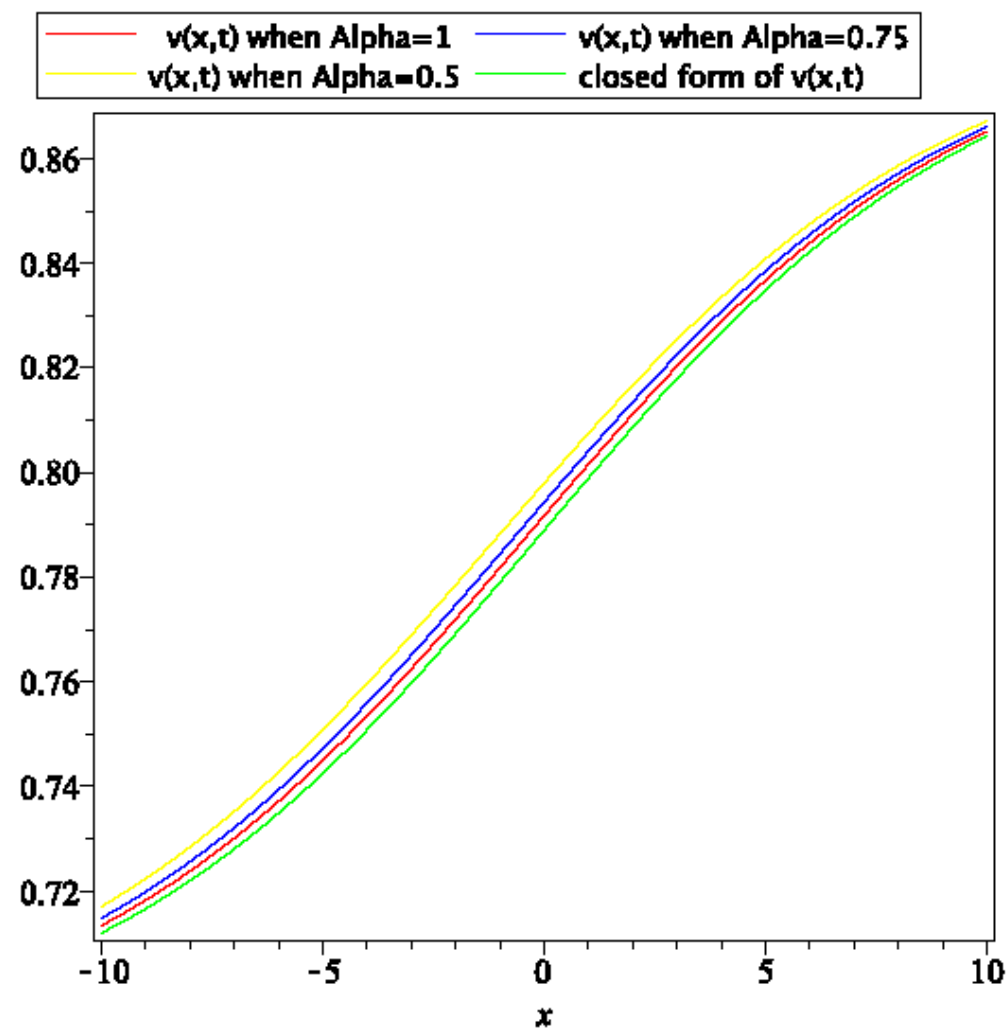

Figure 20-The action of $v(x, t)$ of problems (32)-(35).

\section{Conclusions}

In this study, RPSM was implemented to find the solutions of CD-REs and CMKdv. The approximate solution was given as an infinite FPS. The suggested method introduced an easy manner to find the coefficients of the solution, which converges quickly to the closed form. The numerical results demonstrate the significant feature, efficiency, and reliability of the proposed method for solving CD-REs and CMKdv.

\section{References}

1. Ozturk, O. 2016. A Study on the Damped Free Vibration With Fractional Calculus, Int. J. Appl. Mat. Electron.Comput., 4: 156-159.

2. Rihan, F. A., Lakshmanan, S., Hashish, A. H., Rakkiyappan, R. and Ahmed E. 2015. FractionalOrder Delayed Predator-Prey Systems With Holling Type-II Functional Response, Nonlinear Dyn., 80(1-2): 777-789.

3. Sierociuk, D., Skovranek, T., Macias, M., Podlubny, I., Petras, I., Dzielinski, A. and Ziubinski, P. 2015. Diffusion process modeling by using fractional-order models, Applied Mathematics and Computation, 257: 2-11.

4. Ziaei, E., Farahi, M. H. and Safie, E. 2018. The Approximate Solution of Nonlinear Fractional Optimal Control Problems by Measure Theory Approach. Progress in Fractional Differentiation and Applications, 4(3): 197-209.

5. Miller, K. 1993. An Introduction to the Fractional Calculus and Fractional Differential Equation, Wiley, New York.

6. Monje, C. A., Chen, Y., Vinagre, B. M., Xue, D. and Feliu-Batlle, V. 2010. Fractional-Order Systems and Controls: Fundamentals and Applications, Springer, London. 
7. Podlubny, I. 1999. Fractional Differential Equations: An Introduction to Fractional Derivatives, Fractional Differential Equations, to Methods of Their Solution and Some of Their Applications, Academic Press, San Diego.

8. Khalil, R., Al Horani, M., Yousef, A. and Sababheh, M. 2014. A New Definition of Fractional Derivative, J. Comput. Appl. Math., 264: 65-70.

9. Abdeljawad, T. 2015. On Conformable Fractional Calculus, J. Comput. Appl. Math., 279: 57-66.

10. Abdel-Salam, E., Nouh, M. and Elkholy, E. 2020. Analytical solution to the conformable fractional Lane-Emden type equations arising in astrophysics, Scientific African, 8: e00386.

11. Mahdy, A. M. S., Sweilam, N. H. and Higazy, M. 2020. Approximate solution for solving nonlinear fractional order smoking model, Alexandria Engineering Journal, 59: 739-752.

12. Odibat, Z. and Momani, S. 2008. Modified Homotopy Perturbation Method: Application to Quadratic Riccati Differential Equation of Fractional Order, Chaos, Soliton Fractals, 36(1): 167174.

13. Momani, S. and Odibat, Z. 2007. Numerical Comparison of Methods for Solving Linear Differential Equations of Fractional Order, Chaos, Soliton Fractals, 31(5): 1248-1255.

14. Korpinar, Z., Mustafa, I., Evren, H. and Baleanu, D. 2020. Residual power series algorithm for fractional cancer tumor models, Alexandria Engineering Journal, May (2020).

15. Senol, M., Tasbozan, O. and Kurt, A. 2019. Numerical Solutions of Fractional Burgers' Type Equations with Conformable Derivative, Chinese Journal of Physics, 58: 75-84.

16. Oqielat, M. N., El-Ajou, A., Al-Zhour, Z., Alkhasawneh, R. and Alrabaiah, H. 2020. Series solutions for nonlinear time-fractional Schrodinger equations: Comparisons between conformable and Caputo derivatives. Alexandria Engineering Journal, Feb. 2020.

17. El-Ajou, A., Abu Arqub, O., Al Zhour, Z. and Momani, S. 2013. New Results on Fractional Power Series: Theories and Applications.Entropy, 2013, 15: 5305-5323.

18. Abu Arqub, O., El-Ajou, A., Sami Bataineh, A. and Hashim, I. 2013. A representation of the exact solution of generalized lane-emden equations using a new analytical method. Abstract and Applied Analysis, 2013: 1-10.

19. Owyed, S., Abdou, M. A., Abdel-Aty, A. H., Alharbi, W. and Nekhili, R. 2019. Numerical and approximate solutions for coupled time fractional nonlinear evolutions equations via re duce $\mathrm{d}$ differential transform method.Chaos, Solitons and Fractals, oct. 2019.

20. Abdou, M. A. 2018. Fractional Reduced Differential Transform Method and Its Applications. International Journal of Nonlinear Science, 26(1): 55-64. 